\title{
ЗЕМЛЕТРЯСЕНИЕ В ТЕРИБЕРКЕ 100 ЛЕТ ТОМУ НАЗАД И ВОПРОС О СЕЙСМИЧЕСКОМ ПОТЕНЦИАЛЕ СРЕДНЕГО СЕКТОРА МУРМАНСКОЙ СЕЙСМОГЕННОЙ ЗОНЫ
}

\author{
Никонов А.А. \\ Институт физики Земли РАН, Москва, nikonov@ifz.ru
}

Землетрясения на Мурманском побережье возникают редко. За последнее столетие их известно всего около десяти плюс три слабых события в западном секторе Мурманского побережья в 1956-1963 гг. [12]. На картах сейсмичности региона, в зоне, как правило, показывали только единицы событий. На картах общего сейсмического районирования страны (ОСР-2012, ОСР-2014, ОСР-2016) Мурманское побережье вообще показано как практически безопасное [11], хотя зона была выделена полвека назад [12] и впоследствии многократно подтверждалась разными группами исследователей. Землетрясение 1917 г. в пос. Териберка отсутствует в каталоге [14], но значится в других региональных каталогах $[5,7,17]$. Параметры его определены по одному небольшому сообщению из самого поселка сразу вслед за событием [6], но в определениях его силы имеются расхождения (табл.), объяснений которым не приводилось. Так, например, в первопубликации С.С. Андреева и на его карте 1956 г. землетрясению придано значение интенсивности VI баллов [2]. Магнитуда события в книге Г.Д. Панасенко определена $\mathrm{M}=4.5 \pm 0.5$ [12] и $\mathrm{M}=(4.5) \pm 1$ при $\mathrm{I}=(\mathrm{V}) \pm 1$ [7]. Позднее И.В. Ананьин придавал землетрясению интенсивность I=V-VI баллов, правда, без обоснования [1]. В современных каталогах $[5,17]$ сила события дается V баллов (без каких-либо пояснений). Расхождения побуждают к рассмотрению первичных сведений на уровне современных возможностей, с одной стороны, и важности оценок сейсмической активности Мурманской зоны, с другой.

\section{Фактические сведения и их оценка}

Сведения с места о землетрясении 1917 г. были опубликованы в Архангельске [6], но затем долгие годы не привлекали внимания специалистов. В фактологической части, а именно, по донесению зав. метеостанцией в Териберке в Управление Гидрометеослужбы в Архангельск, они были воспроизведены Г.Д. Панасенко [12], сначала без комментариев, а затем в сопровождении параметрической строки, где I «не менее 5 баллов» и $\mathrm{M}=4.5 \pm 1$ [7] и с пояснениями [13]. Текст сообщения о землетрясении 05.02.1917 г. относительно полно был изложен через полстолетия [12], но тогда не проанализирован, как, впрочем, и позже. Наряду с другими макросейсмическими сведениями с комментариями землетрясение включено в публикацию $[8,16]$, которая в дальнейшем оставалась неиспользованной. Четверть века спустя, имея бо́льший опыт интерпретации, целесообразно пересмотреть исходные сведения заново. Для удобства текст первопубликации воспроизводится в оригинальном виде). Ниже воспроизведена публикация с исходными сведениями [6] (рис. 1).

Землетрясение произошло в середине зимы в полярную ночь, в полночь. Этим объясняется поступление сведений об эффектах только изнутри помещений. Тот факт, что строения располагались на сложенной песками террасе, важен в том отношении, что среди зимы они должны были быть проморожены и поэтому жестко передавали колебания подстилающего кристаллического фундамента, а не гасили их. Уже Г.Д. Панасенко [13] посчитал, что очаг землетрясения находился поблизости, в пределах 50 км.

Нижеприведенный анализ сведений первичного сообщения осуществлен впервые. Сведения даны не от одного наблюдателя, как принималось ранее, а от 4-х жителей поселка, т.е. более разносторонне и с большим набором фактов. Все наблюдатели в ночное время находились внутри помещений. При этом оценка интенсивности сотрясений ныне должна производиться с учетом того, что дома в поселке были деревянные, бревенчатые, очень крепкие, в которых сотрясения ощущаются ослаблено на 1 балл, как это отмечено в шкале MSK-64. С учетом этих обстоятельств интенсивность события в пос. Териберка определяется сравнительно устойчиво, а не приблизительно (в скобках, как показано в каталогах). Соответствующая оценка $\mathrm{I}=\mathrm{VI} \pm 0.5$ баллов с возможной неточностью \pm 0.5 балла, а не V баллов, значение магнитуды $\mathrm{M}=4.6 \pm 0.5$ (табл.). 


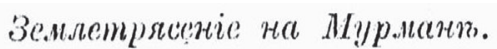

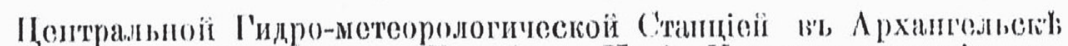

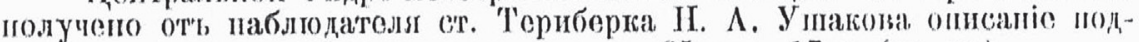

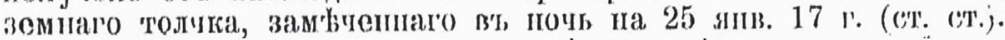

24-25 янз. (ст. ст.), межку $11^{\mathrm{h}} 50$ и $12^{\mathrm{h}} 20$ почи все зданіе стап-

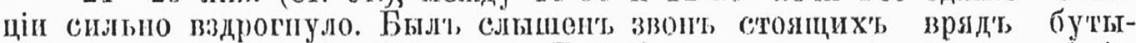

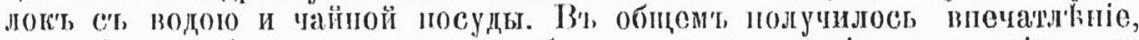

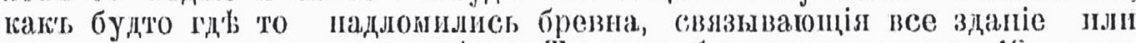
часть его свалилась со с'толбов'ь. 'Толтек'ь был' весьма жесткій, про-

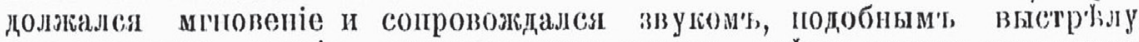

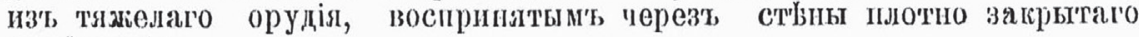
помџщенія.

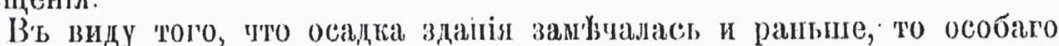

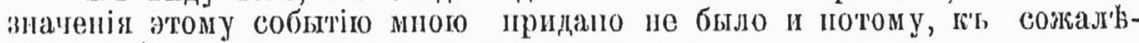
пію, не йл'т точно занисан's момент'ттолчка.

Из'ь разсказов' жителей становица Териберга видио, тто выше отм'зеншый толчек' быльс зам'ычеш'ь и ими, причем'ь колонисть М. С.

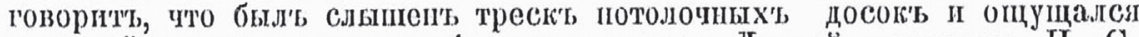

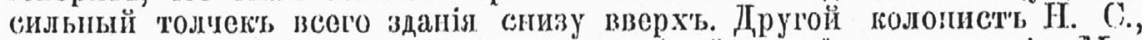

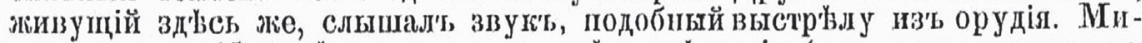

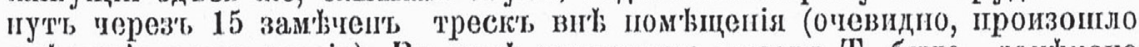

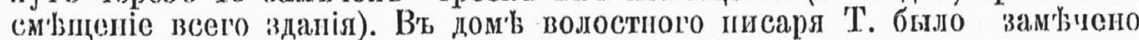
сильос колебаніе весй жилой гостройки в'ь торизонтальном н нацрав-

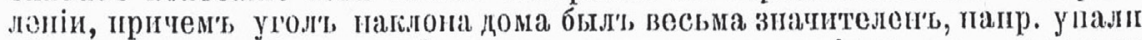

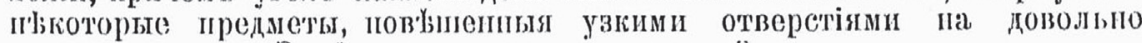

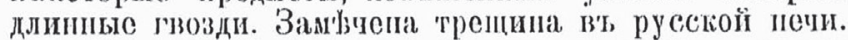

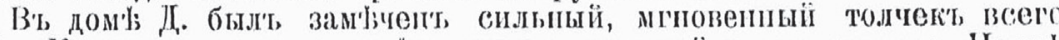

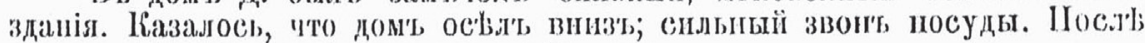
толчка пепродолжительное движепіе пола.

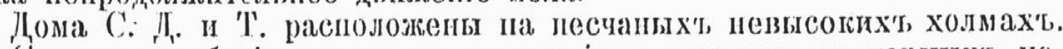

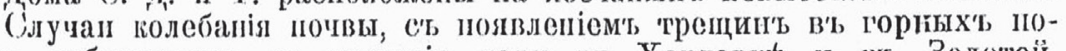
родах'ь наблюдались в'ь прежніс годы в'ь Харловк'в и в'ь Золо'тої. Наблюлатель Н. У Унакон', ${ }^{*}$.

Рис. 1. Текст сообщения Н.А. Ушакова о землетрясении в Териберке в ночь с 5 на 6 февраля 1917 г. [6].

Здания поселка расположены на «невысоких песчаных холмах», т.е. на приморской террасе внутри бухты, а не на скальных породах. Толчок ощущался, снизу вверх, как «весьма жесткий», что неудивительно в условиях промерзшего грунта. Колебания зданий замечены и в горизонтальном направлении. Это дает основание принимать эпицентр вблизи от поселка - в километрах или первых десятках км от него. По формальным признакам сила сотрясения в 4-х разных избах определяется V, V, V-VI, V-VI, но с учетом типа построек должна быть увеличена, как минимум, до VI баллов. Если же эпицентр полагать находящимся в километрах от поселка, то - и больше. Поэтому резонно оценить силу толчка I=VI \pm 0.5 или VI, $5 \pm 0.5$. Принимавшаяся глубина гипоцентра (20) 10-40 км представляется завышенной, глубина большинства землетрясений в регионе определялась в среднем 15-20 км. Поэтому и в данном случае можно считать $\mathrm{h}=15$ (8-25) км. Согласно исходному тексту уточняются и другие параметры события.

Таблица. Параметрические строки землетрясения 05.02.1917 по разным источникам.

\begin{tabular}{|l|c|c|c|c|c|c|}
\hline \multicolumn{1}{|c|}{ Дата } & Время & Координаты & $\mathrm{h}, \mathrm{m}$ & $\mathrm{M}$ & $\mathrm{I0}$ & Ссылка \\
\hline 1917 февр. 05 & $\begin{array}{c}21=50 \\
\pm 1 \text { час }\end{array}$ & $\begin{array}{c}69.1 ; 35.3 \\
\pm 0.5 \pm 1.0\end{array}$ & $\begin{array}{c}(20) \\
10-40\end{array}$ & $\begin{array}{c}(4.5) \\
\pm 1.0\end{array}$ & $\begin{array}{c}\mathrm{V} \\
\pm 1.0\end{array}$ & {$[7]$} \\
\hline 1917. 06. II. & 21 ч 50 мин & & 20 & 4.6 & $\mathrm{~V}$ & {$[17]$} \\
\hline 1917. 06. II. & 21 ч 50 мин & & 20 & 4.6 & $\mathrm{~V}$ & {$[5]$} \\
\hline 1917 февр. 05 & 21 ч 50 мин & $\begin{array}{c}69.1 ; 35.3 \\
\pm 0.1 \pm 0.2\end{array}$ & $\begin{array}{c}(15) \\
8-25\end{array}$ & $\begin{array}{c}4.6 \\
\pm 0.5\end{array}$ & $\begin{array}{c}\text { VI } \\
\pm 0.5\end{array}$ & По автору, 2018 \\
\hline
\end{tabular}

Уместно напомнить также о сейсмическом событии в Териберке спустя 64 г., 10 апреля 1981 г., когда сотрясения там составили около V баллов, а эпицентр определен по инструментальным данным далеко к юго-востоку, около Харловых островов [8]. 
Особого внимания заслуживает последняя фраза в публикации 1917 г.: «случаи колебания почвы, с появлением трещин в горных породах, наблюдались в прежние годы в Харловке и в Золотой» [6], т.е. к востоку от пос. Териберка, в пределах среднего сектора Мурманской зоны. В 1969 г. Г.Д. Панасенко посчитал это сообщение незначащим и оценил «колебания» «по-видимому, в пределах $3<\mathrm{M}<4$ » [12]. При этом основной признак силы воздействий - возникновение трещин - остался не учтен. Хотя и глухое, но это свидетельство наблюдателей реального возникновения не только нескольких «сейсмических колебаний», но и сейсмических трещин (расколов? в связи с ними) в скальных породах, т.е. землетрясений (не просто «колебаний») силой VII баллов, скорее, VII-VIII баллов. Именно так, согласно современной шкале INQUA-2004 [15], оцениваются такие последствия сейсмических событий. Косвенно это можно вывести и из того обстоятельства, что жители пос. Териберка в 1917 году не вспомнили про сотрясения у них в поселке годами раньше, когда землетрясения охватили участок Золотая - Харловка в 70-100 км к юго-востоку от Териберки. На таком расстоянии затухание могло осуществиться, если на востоке сотрясения составляли VII или VII-VIII баллов. Так встает вопрос о сейсмическом потенциале среднего сектора Мурманской зоны.

\section{Вопрос о сейсмическом потенциале среднего сектора Мурманской зоны}

Землетрясение 1917 г. силой VI баллов само по себе опасности не представляет. Но в данном случае столь успокоительное заключение для участка Териберка, как, впрочем, и для всего Мурманского побережья (зоны), в качестве финального принято быть не может. Дело в том, что в последние десятилетия на Териберском участке и по соседству с ним несколькими исследователями и группами исследователей из разных городов и организаций независимо друг от друга обнаружены весьма выразительные сейсмодислокации в скальных породах с возрастом в пределах 10-3 тыс. лет, свидетельствующие о возникновении в районе, точнее, в этой очаговой области неоднократных разрушительных землетрясений прошлого [3, 4 и др.]. В качестве примера см. рис. 2. С точки зрения выделения полосы Мурманского побережья в средней по протяженности его части (в среднем секторе) в качестве сейсмогенной зоны полученные разного рода материалы имеют принципиальное значение $[9,10]$ и требуют специальной проработки. Между тем, в разных инстанциях, без знания этих, принципиально новых, данных, планируются возведение на Териберском участке то новой очереди Кольской АЭС, то трубопроводного терминала, то крупного завода. Как это давно выяснили сейсмологи и палеосейсмологи, в том числе в разных частях Фенноскандинавского щита сильные зем-

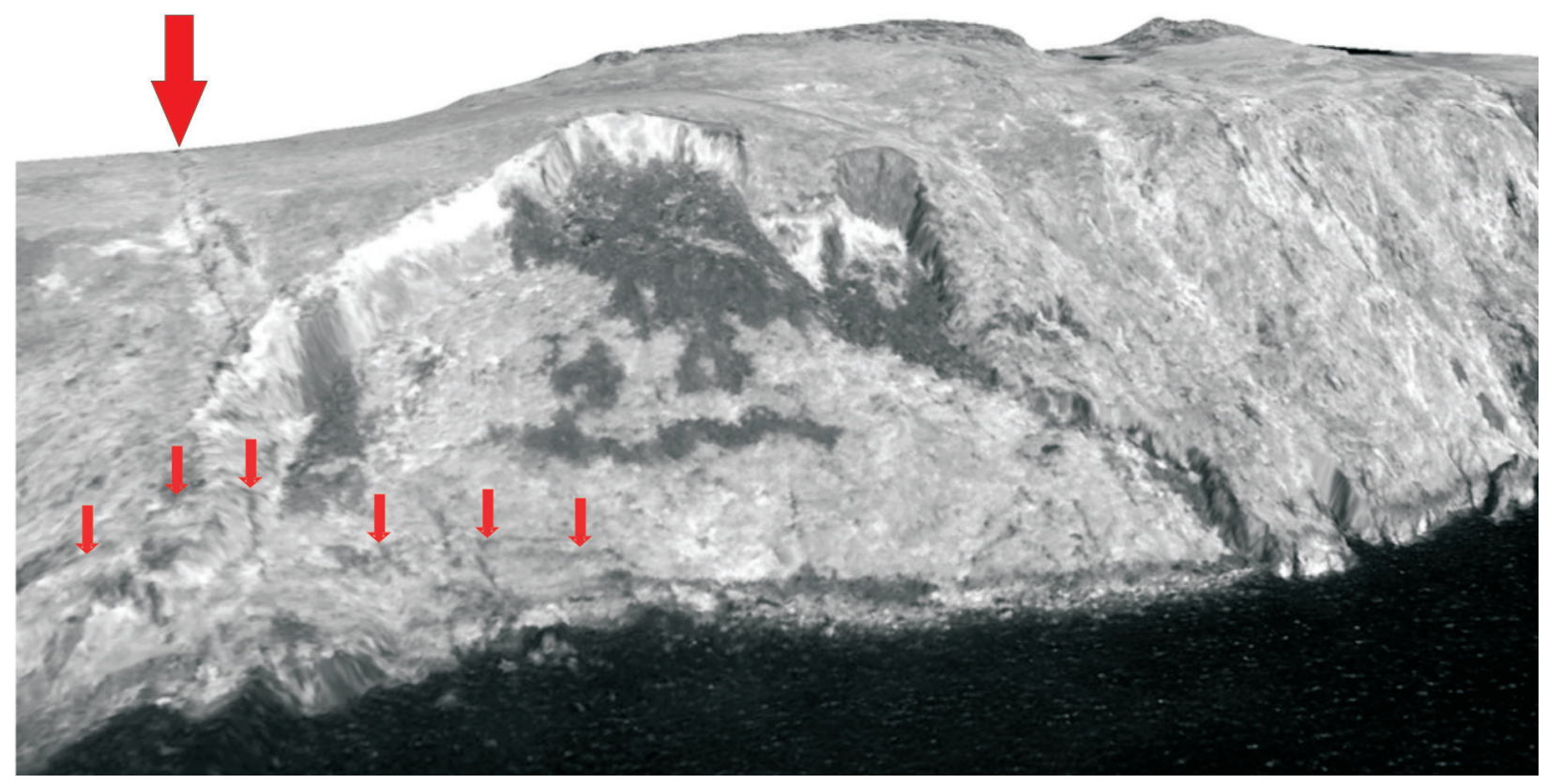

Рис. 2. Окрестности пос. Териберка с крупным скальным оползнем на переднем плане, с обновлением в нижней части (слева, тонкие стрелки). Наверху выход к берегу молодого разлома (толстая стрелка). Фото А.Л. Строма. 
летрясения возникали и обнаруживаются в прошлом в казавшихся ранее асейсмичными и/или слабо сейсмичными областях.

А.Н. Морозов любезно просмотрел бюллетени Европейских сейсмических станций Упсала, Берген, Потсдам, Пулково, Екатеринбург, а также более южных в Европе, но ни одна из них, как оказалось, события 05.02.1917 г. не отметила. Автор весьма признателен А.Н. Морозову за выполненную проверку, С. Ю. Нечаеву за копирование текста [6], А.Л. Строму за предоставленную фотографию и Л.Д. Флейфель за техническую помощь.

\section{Литература}

1. Ананьин И.В. Землетрясения Балтийского щита и особенности их проявления // Сильные землетрясения и сейсмические воздействия. Вопросы инженерной сейсмологии. Вып. 28. М.: Наука, 1987. С. 96-105.

2. Андреев С.С. О сейсмической характеристике Русской платформы // Известия АН СССР. Сер. геофиз. 1956. 12. С. $1484-1487$.

3. Авенариус И.Г. Морфоструктурный анализ при изучении культурного и природного наследия ЗападноАрктического региона России. Паульсен, 2007. 197 с.

4. Верзилин Н.Н., Бобков А.А., Кулькова М.А., Нестеров Е.М., Нестерова Л.А., Мадянова Н.П. О возрасте и образовании современного расчлененного рельефа севера Кольского п-ова // Вестник С-Пб. Ун-та. Cер. 7: Геол. Геогр. 2013. Т. 2. С. 79-93.

5. Землетрясения и микросейсмичность в задачах современной геодинамики Восточно-Европейской платформы. Кн. 1. Под ред. Н.В. Шарова, А.А. Маловичко, Ю.К. Щукина. Петрозаводск. 2007. 381 с.

6. Известия Архангельского общества изучения Русского Севера. 1917. № 3-4. С. 174-175.

7. Новый каталог сильных землетрясений на территории СССР с древнейших времен до 1975 г. М.: Наука, 1977. $536 \mathrm{c.}$.

8. Никонов А.А. Макросейсмическая характеристика землетрясений XX в. в восточной части Балтийского щита // Белорусский сейсмол. бюлл. 1992. Вып. 2. С. 96-144.

9. Никонов А.А., Зыков Д.С., Николаева С.Б., Шварев С.В. Шовная зона «Линия Карпинского» - Трольфьорд на севере Европы как активный тектонически и сейсмически сейсмолинеамент высшего порядка / Проблемы тектоники и геодинамики земной коры и мантии. Матер. L Тектонического совещания. T. 2. М.: ГEOC. 2018. C. 52-55.

10. Никонов А.А., Шварев С.В., Николаева С.Б. Мурманское побережье - крупнейшая в Российской Арктике сейсмогенерирующая зона: новейшие разработки / Природные ресурсы и комплексное освоение прибрежный районов Арктической зоны. Сб. научных трудов. Отв. ред. В.И. Павленко. Архангельск. 2015. С. 34-40.

11. Объяснительная записка к комплекту карт ОСР-2016 и список населенных пунктов, расположенных в сейсмоактивных зонах. Общее сейсмическое районирование территории Российской Федерации // Инженерные изыскания. 2016. № 7. С. 49-121.

12. Панасенко Г.Д. Сейсмические особенности северо-востока Балтийского щита. Л.: Наука. 1969. 185 с.

13. Панасенко Г.Д. Сейсмичность восточной части Балтийского щита / Сейсмичность и современные движения земной коры восточной части Балтийского щита. Апатиты. 1980. С. 7-24.

14. Båth M. An earthquake catalogue for Fennoscandia, the years 1894-1950 // Sver. Geol. Unders. Ser. C. 1956. 545 s.

15. Michetti A.M., Esposito E., Gürpinar A. et al. The INQUA scale. An innovative approach for assessing earthquake intensities based on seismically induced ground effects in natural environment / Special paper APAT. Memorie descritive della carta geologica d'Italia. Roma, 2004. V. LXVII.

16. Nikonov A.A. Felt effects for earthquakes of the 20th century in the Eastern Baltic Shield / Report Inst. Seismology, University of Helsinki. S-27. Helsinki, 1991. P. 1-30.

17. Special earthquakes catalog. Eds. Kondorskaya, Ulomov. 1996. 